\title{
The National Center for Research to Improve Postsecondary Teaching and Learning (NCRIPTAL)
}

Editorial Note: The information for this occasional feature was provided by the subject(s) of the feature. The editors wish to thank Mary Joscelyn of the University of Michigan for making this information available to us. In the following, the editors of J.E.T.T. ask the questions about NCRIPTAL that have been asked of us.

J.E.T.T.: Define who you are in a paragraph.

NCRIPTAL: In a quest for excellence in education, the United States government has funded several national centers to study various aspects of education. NCRIPTAL (the National Center for Research to Improve Postsecondary Teaching and Learning) is a project co-sponsored by the University of Michigan and the federal Office of Educational Research and Improvement (formerly, the National Institute of Education) to research, develop, and disseminate methods to improve college education. As a national center established by the U.S. Department of Education, NCRIPTAL focuses on ways to improve teaching and learning, primarily in two- and four-year colleges.

J.E.T.T.: What aspects of postsecondary education does NCRIPTAL focus on?

NCRIPTAL: Our research programs focus on 1) teaching and learning; 2) curriculum; 3) faculty; 4) organizational context; and 5) technology.

J.E.T.T.: Since NCRIPTAL was established by an agency of the federal government, has Washington dictated that you pursue a specific research agenda?
NCRIPTAL: No. We establish our own research agenda, with help from colleges of all types. We accept, however, our tripartite charge to: provide national leadership and encourage research, conduct selected research projects in collaboration with colleges, and provide suggestions for improvement.

J.E.T.T.: The five areas of postsecondary education which comprise your research focus are aspects all of us in higher education encounter. Can you define each of the five research areas in greater detail?

NCRIPTAL: In the area of teaching and learning, our program on Instructional Processes and Educational Outcomes explores how such student characteristics as learning strategies, motivation, personality, stages of intellectual development affect learning. This program's work is grounded in cognitive theory, personality theory, and developmental theory. The major projects under this program are studies of: 1) teaching and learning strategies; 2) student involvement and appraisal of learning environments; and 3) individual differences and intellectual development.

In the area of curriculum, our program on Curricular Integration and Student Goals studies the extent to which the organization and integration of academic content interact with student and program goals to affect learning. Specific projects include research on: 1) dimensions of academic program structure; 2) curriculum research across disciplines; 3) mapping student educational goals; 4) testing a curriculum impact model; and 5) integrating liberal and occupational study. 
In the area of faculty, our program on Faculty as a Key Resource examines the effects of faculty characteristics and methods on learning to determine how these effects can be assessed and altered to improve learning. Major projects of this program include inquiry into: 1) psychological aspects of teaching; 2) expanding teaching skills through teaching assessment and feedback; and 3) teaching climate, rewards, and role integration.

In the area of organizational context, our program on the Organizational Context for Teaching and Learning identifies organizational practices within colleges that support and foster a climate for successful teaching and learning. The projects designed to assess and improve these practices include: 1) an exploration of organizational practices; 2) a national survey of organizational practices; 3 ) academic climate and student outcomes; and 4) strategies for improving academic climate.

And finally, in the area of technology, our program on Learning, Teaching, and Technology seeks to assess current and potential uses of technology. The program will initiate a national dialogue among college faculty members on "information literacy," develop a taxonomy of software, and sponsor conferences at which faculty and software developers can identify effective learning materials. The three major projects planned in this program are on: 1) use of technology in college instruction; 2) utility of technology in college instruction; and 3) information literacy.

\section{J.E.T.T.: Does NCRIPTAL make its findings available to people in the profession?}

NCRIPTAL: Yes. The NCRIPTAL staff develops general position papers, working papers, and reviews in each of the five areas of research focus. These are available upon request (at the cost of reproduction) from NCRIPTAL, 2400 School of Education Building, The University of Michigan, Ann Arbor, Michigan 48109-1259.

J.E.T.T.: What are some of the position and working papers available upon request?

NCRIPTAL: Approaches to Research on the Improvement of Postsecondary Teaching and
Learning: $A$ Working Paper by Patricia J. Green and Joan S. Stark (Technical Report 86-A-001.0) is available for $\$ 5.00$ and addresses the recent concern about the quality of college education. Concern with the quality of education prompts research on causes and cures. The causes identified, however, depend on the questions asked and on the methods used to find answers. Are the causes of decline in the process of teaching and learning itself, the people involved, the organizations, or perhaps in the definition of a collegeeducated person? Are the answers best found through basic research, institutional research, policy analysis, evaluation, or some combination of these.

Focusing on Student Academic Outcomes: A Working Paper by Joanne M. Alexander and Joan S. Stark (Technical Report 86-A-002.0) is available for $\$ 5.00$. Current pressures to "assess" the outcomes of college education are complicated by different definitions of assessment and by confusion between policy issues and educational issues. This working paper defines assessment as a process of measurement and evaluation with eight identifiable parameters. Outcomes of college education relate to social, personal, and academic development of individuals and can be measured by changes in cognition, motivation, and behavior. NCRIPTAL programs focus on academic outcomes.

Postsecondary Teaching and Learning Issues in Search of Researchers: $A$ Working Paper by Carol D. Vogel and Joan S. Stark (Technical Report 86-A-003.0) is available for $\$ 5.00$. The research staff at NCRIPTAL defined a preliminary universe of issues related to teaching and learning. The universe was organized into five fields related to the programs at the Center. From these fields specific issues were selected. This working paper presents the issues, cites important works for both researchers and practitioners, and mentions a wide variety of important issues that other researchers might consider addressing.

Teaching and Learning in the College Classroom: A Review of the Research Literature by Wilbert J. McKeachie, Paul R. Pintrich, Yi-Guang Lin, and David A.F. Smith (Technical Report $86-\mathrm{B}-001.0)$ is available for $\$ 10.00$. The "best" teaching method depends on such variables as 
student characteristics, goals to be achieved, the teacher, and the content matter to be taught. Research indicates ways of measuring and altering these variables.

Psychological Models of the Impact of College on Students by Harold A. Korn (Technical Report 86-B-002.0) is available for $\$ 5.00$ and describes five perspectives on the impact of college on students, along with theoretical and methodological issues these perspectives raise. Two theoretical models, based in cognitive psychology, and issues that must be addressed before the impact of college on the lives of individual students can be studied are presented by the author.

Designing the Learning Plan: A Review of Research and Theory Related to College Curricula by Joan S. Stark and Malcolm A. Lowther, with assistance from Sally Smith (Technical Report 86-C-001.0) is available for $\$ 10.00$. Recent national reports imply the need for curricular changes, but little research describes how such changes might affect teaching and learning or what must be taught to produce educated graduates. In addition to the variables specific to each academic discipline and the capabilities believed to be important in that discipline, variables related to student development and experiences present a complex puzzle for researchers. A perspective of curriculum development broader than that of the individual disciplines holds promise for a better understanding of higher education. Both higher education and pre-college curriculum literature was reviewed in forming a model for further research.

Faculty as a Key Resource: A Review of the Research Literature by Robert T. Blackburn, Janet H. Lawrence, Steven Ross, Virginia Polk Okoloko, Jeffery P. Bieber, Rosalie Meiland, and Terry Street (Technical Report 86-D-001.0) is available for $\$ 10.00$. A review of the literature shows that existing research on faculty members as a group focuses on evaluations of their teaching rather than on what motivates them to do what they do. To gain a broad perspective on faculty motivation and effectiveness, research on professionals in other organizations was included in the review.
J.E.T.T.: Many of our readers deal with and are concerned about learning, teaching, and technology. NCRIPTAL and EDUCOM, a consortium encouraging computer use in colleges and universities, have formed a collaboration. Can you describe this collaboration for our readers?

NCRIPTAL: Our program on Learning, Teaching, and Technology has as its global objective to study and promote the appropriate use of computer technology in college education. One project in this program, Effective Technology, researches the design of educational software and those features that make it effective for particular students and tasks. This program, in collaboration with EDUCOM, is responsible for an awards program established in 1987 by NCRIPTAL and EDUCOM to encourage the development of educationally and technically sound software for higher education.

\section{J.E.T.T.: Where can our readers get informa- tion about the EDUCOM/NCRIPTAL Higher Education Software Awards?}

NCRIPTAL: Technical Report 87-F-003.0 (available from NCRIPTAL for \$10.00) presents the rationale for the program, the criteria for the awards, and the judging process along with descriptions of the 27 winning packages of the 1987 awards. This report is entitled 1987 EDUCOM/NCRIPTAL Higher Education Software Awards. In addition, we publish the Directory of Software Submitted for the 1987 EDUCOM/NCRIPTAL Higher Education Awards. This directory is available in the following formats: printed copy (No. 87-F-004.0) for \$10.00; Macintosh/Microsoft File data diskette (No. 87-F-004.A) for \$10.00; and MS-DOS, ASCII, 5.25" diskette (No. 87-F-004.B) for $\$ 10.00$. A cross-indexed directory, this volume includes detailed information on all software submitted to the competition. NCRIPTAL also makes available The Best of ' 87 , a 29-minute videotape by Jerome Johnston and Susan Gardner, which consists of highlights from the 27 award-winning software packages. Winning packages include software for biology, chemistry, English composition, ecology, history, journalism, mathematics, physical sciences, physics, psychology, physiology, social science, and 
statistics. This videotape is available in VHS format (No. 87-F-005.V1) for $\$ 25.00$ and in Umatic or 3/4" format (No. 87-F-005.U1) for $\$ 40.00$.

\section{J.E.T.T.: Who supports the EDUCOM/ NCRIPTAL Higher Education Awards financially?}

NCRIPTAL: Financial support for the awards program has come from NeXT, Inc., Annenberg/ CPB Project, and Apple Computer, Inc.

J.E.T.T.: For more information about the EDUCOM/NCRIPTAL Higher Education Awards, our readers may contact whom?

NCRIPTAL: Readers may write to: Robert Kozma, 2610 School of Education, University of Michigan-Ann Arbor, Ann Arbor, MI 48109. For information about EDUCOM, readers may write to: EDUCOM, 777 Alexander Road, P.O. Box 364, Princeton, NJ 08540.
J.E.T.T.: Can you tell our readers something about your Electronic Classroom series?

NCRIPTAL: The Electronic Classroom is a series of four videotapes (either VHS or 3/4" format) showing current uses of electronic technology in teaching. The first three tapes each present technology uses in a specific type of institution: a research university, a comprehensive, teaching university, and a community college. The fourth tape presents an overview of technology in undergraduate teaching and includes examples from liberal arts colleges. The hour-long tapes show computers in use, including excerpts of specific programs, speculate on future developments, and discuss such issues as costs and benefits, patterns of growth, and impact on institutions, curricula, faculty and students. Prices for this videotape series are available upon request from NCRIPTAL, 2400 School of Education Building, The University of Michigan, Ann Arbor, Michigan 48109-1259, (313) 936-2741. 